\title{
Development of scatterometer-derived surface pressures for the Southern Ocean
}

\author{
Kyle A. Hilburn, ${ }^{1}$ Mark A. Bourassa, and James J. O’Brien \\ Center for Ocean Atmospheric Prediction Studies, Florida State University, Tallahassee, Florida, USA
}

Received 8 January 2003; revised 22 April 2003; accepted 30 April 2003; published 29 July 2003.

[1] High-resolution, research-quality surface pressures are objectively calculated over the Southern Ocean using winds derived from the SeaWinds scatterometer on the QuikSCAT satellite. The pressure fields are validated in comparison to in situ observations. Overall, the scatterometer-derived surface pressures are a small improvement over the National Centers for Environmental Prediction/National Center for Atmospheric Research (NCEP/NCAR) reanalysis, which is used as the objective technique's background field. This improvement is understated primarily because the comparison data undersample storms. Instances are found where the NCEP/NCAR reanalysis misses storms entirely and the scatterometer-derived pressures are a large improvement (as much as $20 \mathrm{hPa}$ ). INDEX TERMS: 3337 Meteorology and Atmospheric Dynamics: Numerical modeling and data assimilation; 0350 Atmospheric Composition and Structure: Pressure, density, and temperature; 3360 Meteorology and Atmospheric Dynamics: Remote sensing; 4275 Oceanography: General: Remote sensing and electromagnetic processes (0689); KEYWORDS: scatterometer, surface pressure, variational techniques, Southern Ocean, SeaWinds, QuikSCAT

Citation: Hilburn, K. A., M. A. Bourassa, and J. J. O'Brien, Development of scatterometer-derived surface pressures for the Southern Ocean, J. Geophys. Res., 108(C7), 3244, doi:10.1029/2003JC001772, 2003.

\section{Introduction}

[2] The scarcity of observations over the oceans has long frustrated meteorological research in the Southern Hemisphere. Launched in 1999, the SeaWinds scatterometer on the QuikSCAT satellite provides unprecedented coverage of the Southern Ocean (Figure 1). The SeaWinds scatterometer actively measures radar backscatter at multiple viewing geometries and polarizations. This information has been used to determine high-quality surface wind speed and direction [Bourassa et al., 1997; Freilich and Dunbar, 1999; Bourassa et al., 2003]. While the wind fields contain a good deal of meteorological information, it is difficult to educe this information by visual inspection of wind vector plots. Traditionally, surface pressure fields have received more attention from meteorologists than wind fields. Thus it would be of value to the meteorological community to derive surface pressure fields from the scatterometer-derived winds. The surface pressure fields could then be used along with the wind fields to gain the maximum information. This paper examines the calculation of surface pressures from scatterometer-derived winds.

[3] Endlich et al. [1981] were among the first to derive surface pressures from scatterometer-derived winds. Seasat-A scatterometer (SASS) wind measurements were objectively analyzed onto a regular grid. The nonlinear balance equation was then solved to yield surface pressures.

\footnotetext{
${ }^{1}$ Now at Remote Sensing Systems, Santa Rosa, California, USA.
}

Copyright 2003 by the American Geophysical Union. 0148-0227/03/2003JC001772\$09.00
They obtained reasonable results, although their method suffered from the deficiency of not accounting for the atmospheric boundary layer. The boundary layer was accounted for in the work of Brown and Zeng [1994], who inverted a boundary layer model with the European Space Agency's (ESA) Remote Sensing Satellite (ERS-1) winds as a lower boundary condition. A pressure field was found with the constraint that it minimized the difference between the geostrophic wind defined by the pressure field and the winds retrieved from inverting the boundary layer model. One weakness of their method was that the winds retrieved from the model were closer to gradient winds than to geostrophic winds. This weakness can be removed by applying a gradient wind adjustment [Patoux and Brown, 2002].

[4] The method used in this paper was originally developed by Harlan and O'Brien [1986], improved by Zierden et al. [2000], and is developed further herein. The Harlan and O'Brien method takes a variational approach to smoothly blend vorticity from the scatterometer-derived winds with geostrophic vorticity from an existing pressure analysis. The method accounts for the boundary layer in a simple way that assumes neutral stratification and barotropic conditions. Although these assumptions seem crude, they eliminate the need for upper air or temperature data, which are likely to be seriously inaccurate in the most interesting cases when the scatterometer differs greatly from the existing analysis. The Harlan and O'Brien method also has the strength of not requiring any iteration when applying a gradient wind adjustment as in the work by Patoux and Brown [2002].

[5] This study has two goals. First is a demonstration that the scatterometer can be effectively used to calculate highresolution, research-quality surface pressure fields without 


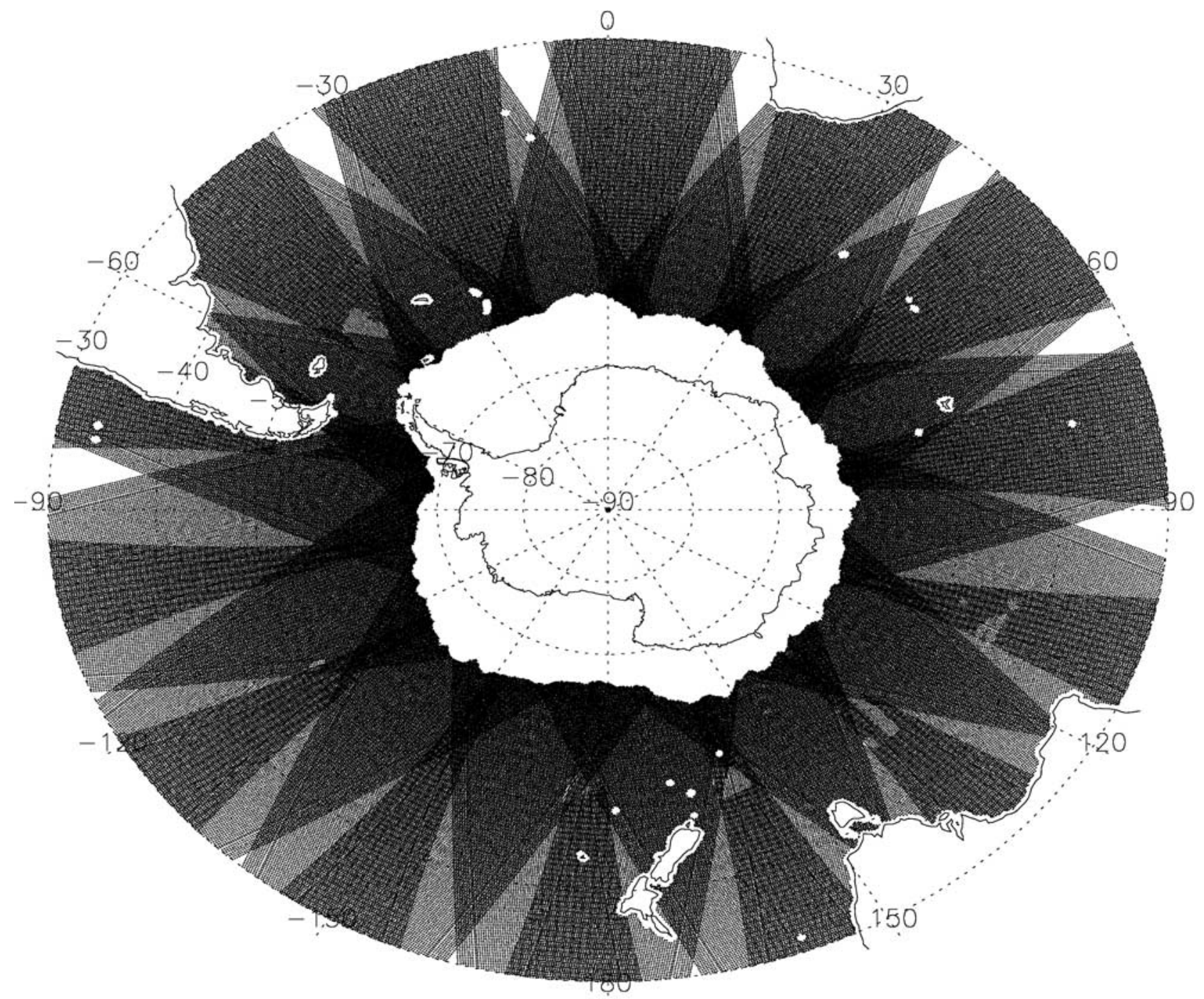

Figure 1. An example of daily SeaWinds on QuikSCAT swath coverage over the Southern Hemisphere south of $30^{\circ} \mathrm{S}$. Note the presence of the ice shelf surrounding Antarctica.

thousands of buoys. Second is a demonstration that the scatterometer has an impact on existing analysis covering the Southern Ocean. To these ends, the following plan is adopted. The scatterometer data and in situ comparison data are described in section 2. The variational method is developed in section 3. Section 4 compares the calculated scatterometer pressures with in situ comparison data. Small statistical improvements over the existing analysis are found, but it is argued that these improvements are underestimated and this is supported by a brief case study in section 5 .

\section{Data}

[6] This study uses winds derived from SeaWinds on QuikSCAT with the Ku-2001 model function [Wentz and Smith, 1999]. Wind vectors are given in $25 \times 25 \mathrm{~km}$ wind vector cells with as many as 76 cells across the satellite swath. Cells flagged as rain contaminated by the radiometer rain flag were not considered in the analysis. While the radiometer rain flag is considered good where available, there are many instances in which it is not available. In instances where rain contaminated winds were used, the regularization term in the variational method (section 3) prevented spurious high-wave number features from appearing in the pressure fields.

[7] The National Centers for Environmental PredictionNational Center for Atmospheric Research reanalysis (NCEPR) is used as the background pressure field for the variational method [Kalnay et al., 1996]. The reanalysis data are available on a $2.5^{\circ}$ global grid at 6 -hour intervals. Linear interpolation in time is used to obtain the pressure field corresponding to the time of the QuikSCAT overpass. The National Climatic Data Center (NCDC) TD1129 marine observations are used as the comparison data in this study. Nearly all of the observations are ship borne. Although these observations may have entered the NCEPR, they have a small effect on Southern Hemisphere analysis as evidenced by their relatively small correlation (Figure 2). The fact that some correlation does exist and the comparison data and background field are not completely independent implies that the validation will tend to understate the 


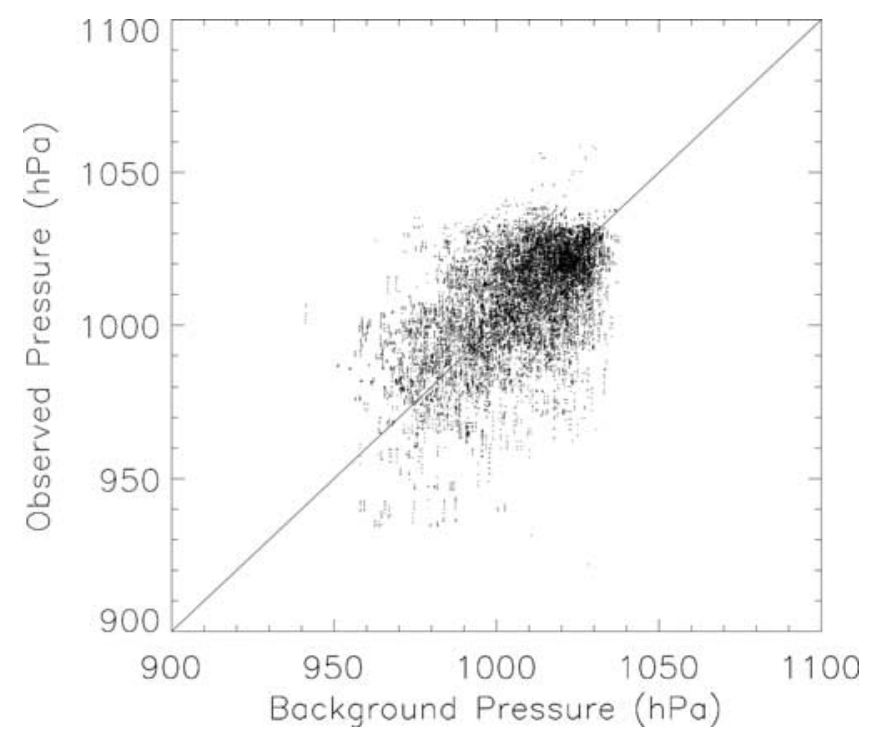

Figure 2. Plot of the observed pressure against the background pressure $\left(r^{2}=0.35\right.$ and $\left.n=25,721\right)$.

improvement of the scatterometer-derived pressures over the existing background pressures.

\section{Methodology}

[8] Surface pressures are calculated from QuikSCAT winds using a variational technique that follows Harlan and O'Brien [1986] and Zierden et al. [2000]. The variational method minimizes a cost function,

$$
F\left(p_{i j}, \zeta_{i j}, \lambda_{i j}\right)=\sum_{i} \sum_{j}\left[\lambda_{i j} H_{i j}+\frac{K_{\zeta}}{2} M_{i j}^{2}+\frac{K_{E}}{2} G_{i j}\right]
$$

$H_{i j}$ is the strong constraint or model [Sasaki, 1970] and has the form

$$
H_{i j}=\frac{1}{\rho f_{j}}\left[\nabla^{2} p_{i j}-\left(\frac{\beta_{j}}{f_{j}}\right) \frac{\partial p_{i j}}{\partial y}\right]-\zeta_{i j},
$$

where $p_{i j}$ and $\zeta_{i j}$ are the solution pressure and solution geostrophic vorticity fields and $f_{j}$ and $b_{j}$ are the Coriolis and beta parameters. $\lambda_{i j}$ are the Lagrange multipliers. The data misfit term has the form

$$
M_{i j}=\zeta_{i j}-\left(\zeta_{i j}^{*}\right)_{g}
$$

The geostrophic vorticity from data, $\left(\zeta_{i j}^{*}\right)_{g}$, takes on the satellite value, $\left(\zeta_{i j}^{S}\right)_{g}$, inside the swath and the background value, $\left(\zeta_{i j}^{B}\right)_{g}$, outside the swath. The background geostrophic vorticity is easily calculated using the relationship

$$
\left(\zeta_{i j}^{B}\right)_{g}=\frac{1}{\rho f_{j}}\left[\nabla^{2} p_{i j}-\left(\frac{\beta_{j}}{f_{j}}\right) \frac{\partial p_{i j}}{\partial y}\right] .
$$

Calculation of the geostrophic vorticity from the satellite is more involved and will be described in the next paragraph.

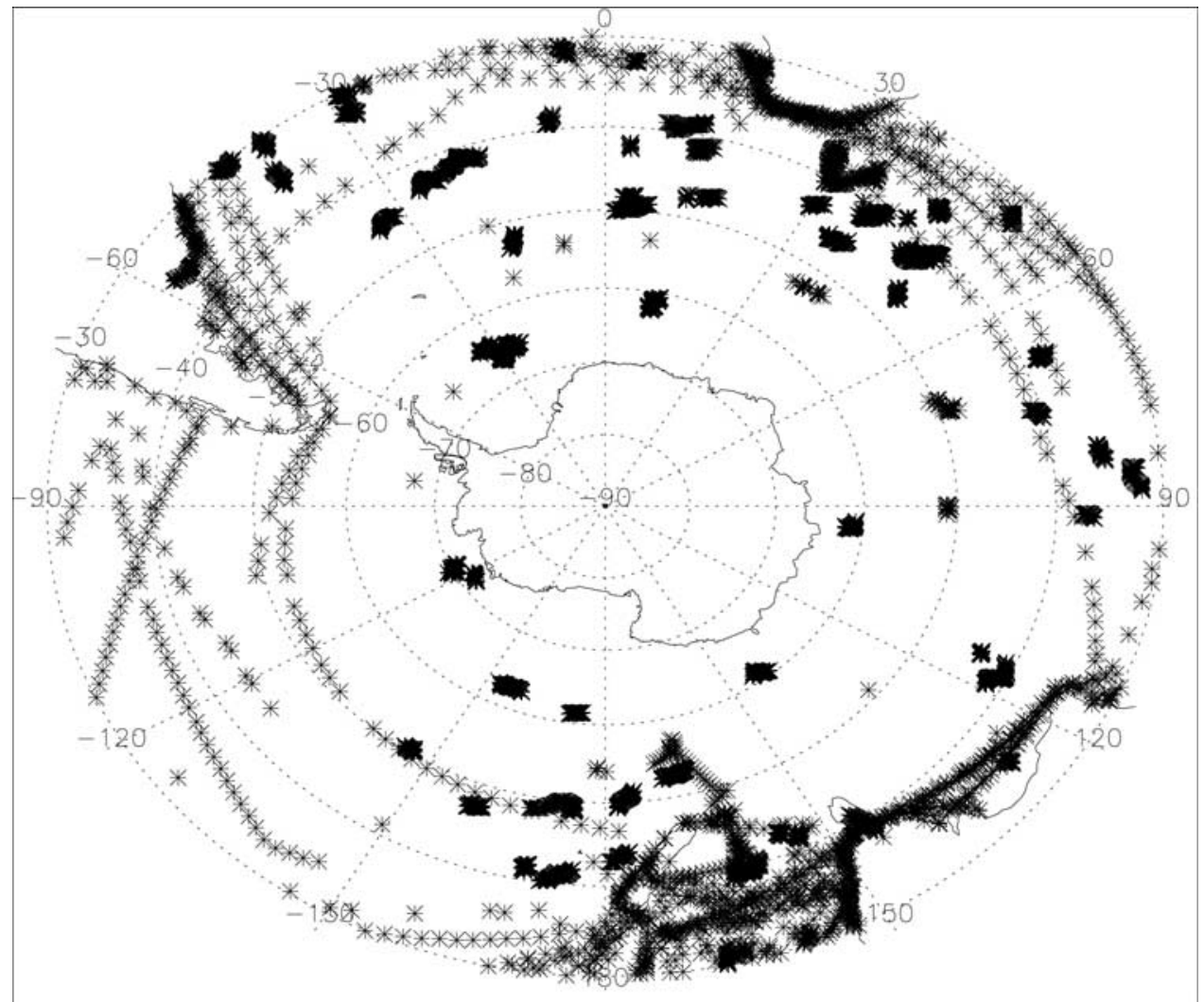

Figure 3. Plot showing the locations of in situ observations used for validation. 
Table 1. Statistics for the Calculated, Background, and Observed Pressures and Their Differences

\begin{tabular}{llc}
\hline \multicolumn{1}{c}{ Quantity } & Mean & RMS Difference \\
\hline Observed & 1009.08 & 16.95 \\
Calculated & 1006.09 & 14.75 \\
Background & 1007.62 & 16.37 \\
Calculated-observed & -3.00 & 13.96 \\
Background-observed & -1.45 & 15.10 \\
Calculated-background & -1.55 & 5.43 \\
\hline
\end{tabular}

Finally, a regularization term is included so that the scatterometer vorticity is blended with the background vorticity. Without such a term, the only solution is $\lambda=0$, and the satellite vorticity would be inserted directly into the field. There are many choices for regularization, but minimization of the geostrophic kinetic energy has been found to be successful [e.g., Zierden et al., 2000; Harlan and O'Brien, 1986],

$$
G_{i j}=\frac{1}{2 \rho^{2} f_{j}^{2}} \nabla p_{i j} \bullet \nabla p_{i j}
$$

The coefficients $K_{\zeta}$ and $K_{E}$ are the Gaussian precision modulii, and their ratio controls the relative amounts of smoothing to data misfit. Note that $K_{\zeta}$ and $K_{E}$ are also required for dimensional homogeneity. All calculations involving the satellite winds are done on the observational grid, which has a regular $\sim 25 \mathrm{~km}$ spacing. Delaunay triangulation and interpolation [Renka, 1982] transfers the background and satellite vorticity onto a regular $0.25^{\circ}$ earth-aligned grid just prior to minimizing the cost function.

[9] The satellite winds are adjusted to geostrophic values according to the following procedure. First, a boundary

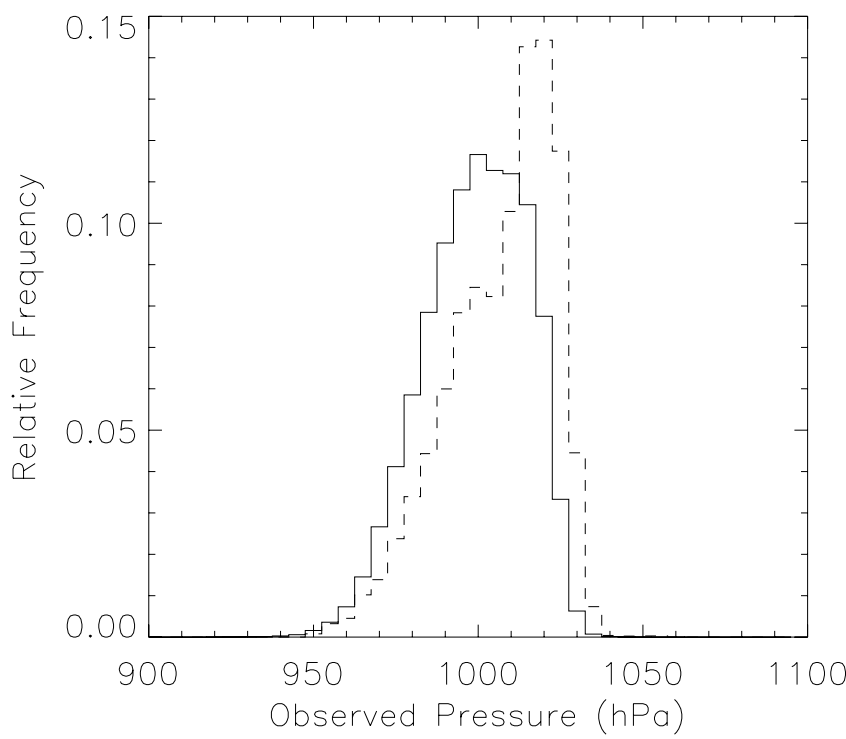

Figure 4. Histograms for all calculated pressure points (solid line) and observation pressure points (dashed line). It can be seen that all the calculated pressure points include low pressure not found at the validation (observation) points.

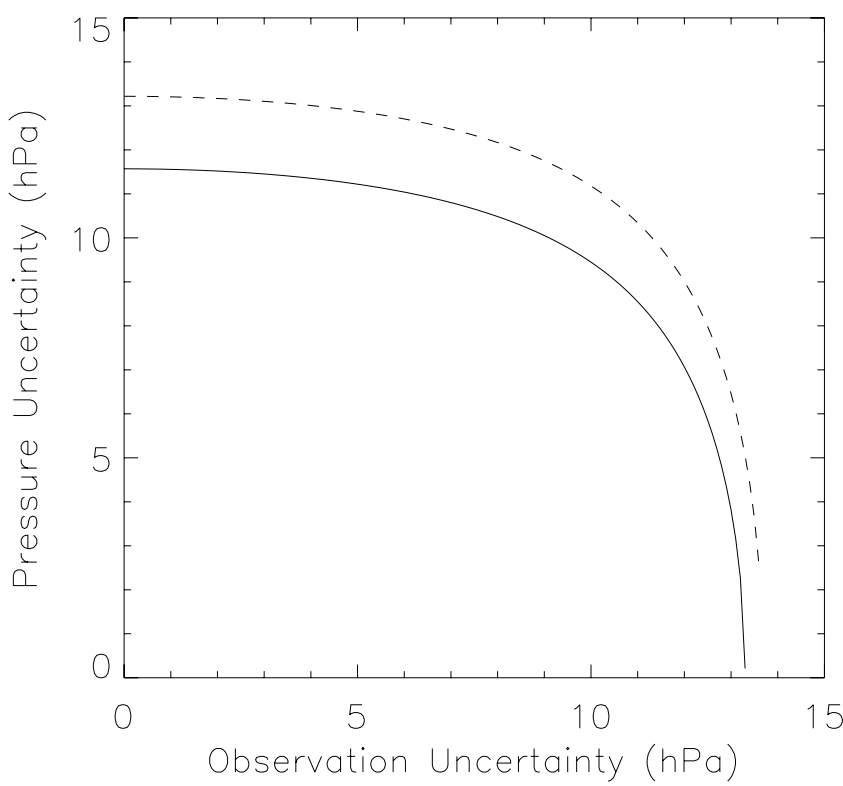

Figure 5. Estimate of the calculated (solid line) and NCEPR (dashed line) pressure uncertainties for a range of observation uncertainties.

layer adjustment transforms the 10-m equivalent neutral [Verschell et al., 1999] scatterometer-derived winds to gradient winds at the top of the boundary layer. The boundary layer adjustment consists of an anticyclonic rotation of the wind direction by $18^{\circ}$ and scaling of the wind speed by 1.5 , which were suggested by theoretical

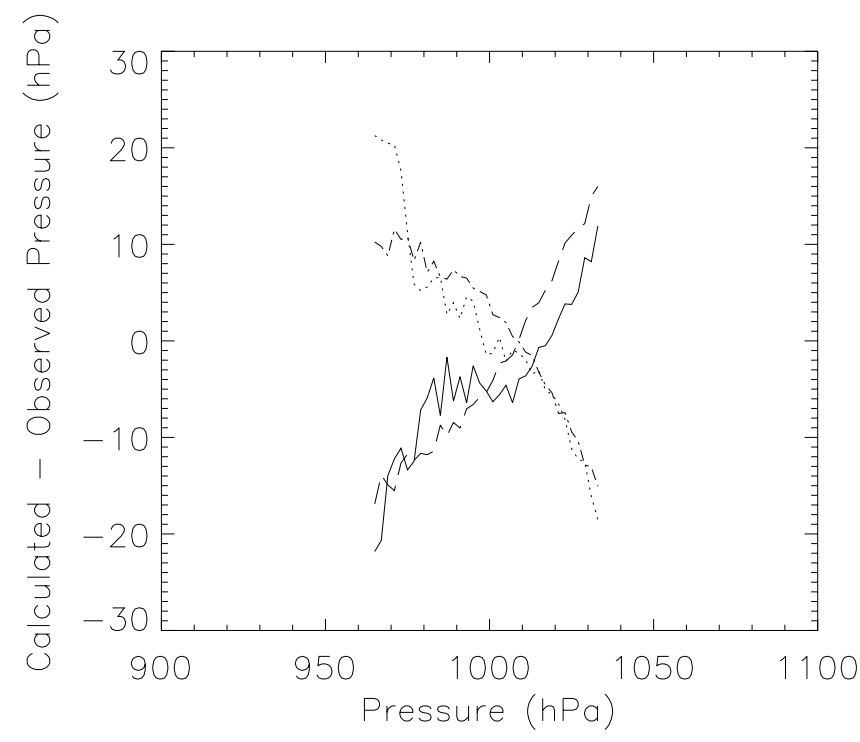

Figure 6. Bin-average analysis using the calculated pressure (solid line), observed pressure (dotted line), synthetic calculated pressure (dashed line), and synthetic observed pressure (dash-dotted line). The synthetic data for this figure used a SeaWinds calculated pressure uncertainty of $11.5 \mathrm{hPa}$ and an observed pressure uncertainty of $13.5 \mathrm{hPa}$, which are the upper limit on the uncertainties (see text for further explanation). 

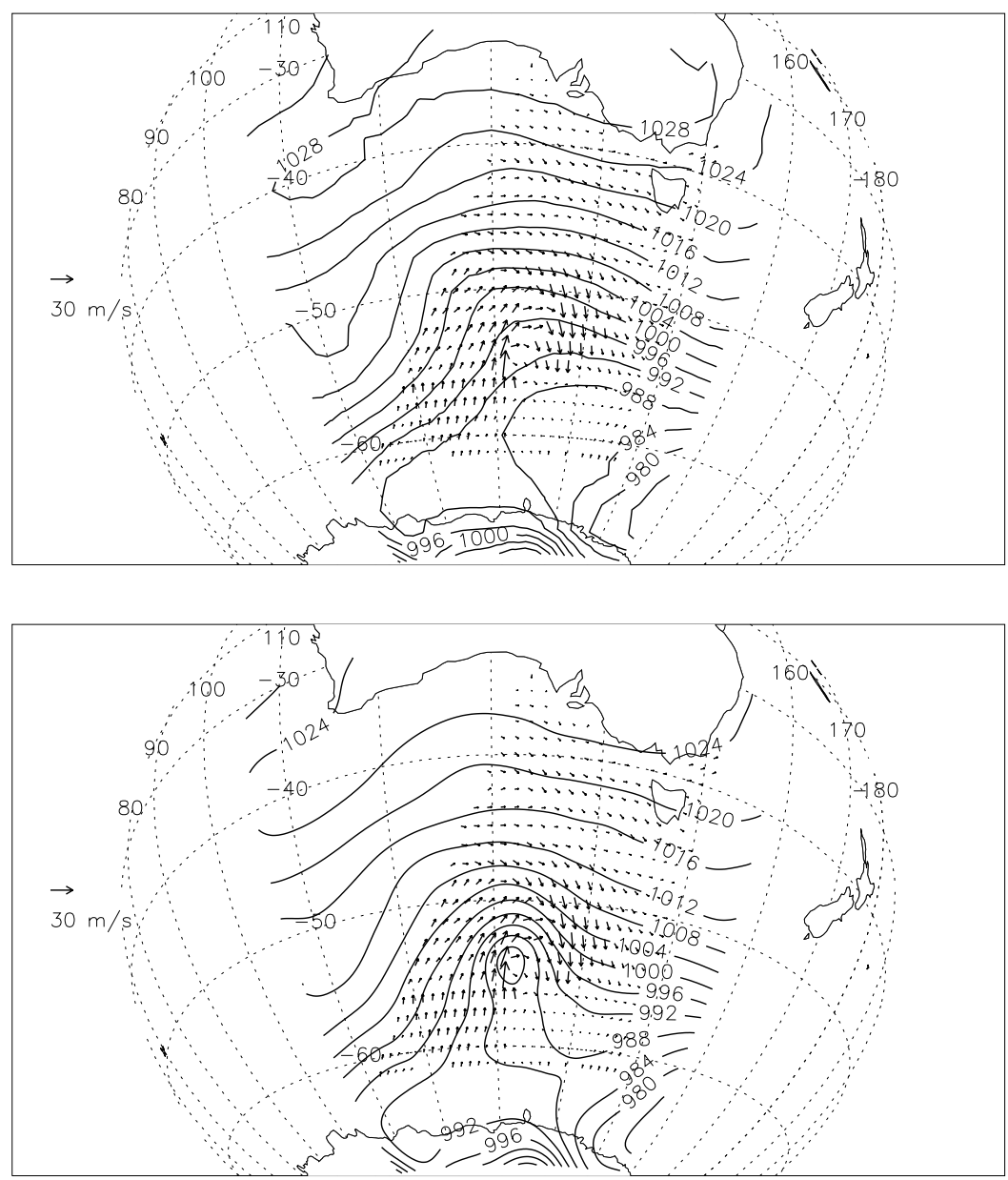

Figure 7. SeaWinds derived winds with (top) NCEPR pressures and (bottom) calculated pressures for 08:06Z 7 June 2000. The southern limit of the swath indicates the location of the ice edge. Contour interval: $4 \mathrm{hPa}$. Central pressure: calculated $982 \mathrm{hPa}$.

considerations for neutral stability and barotropic conditions [Brown and Zeng, 1994]. Although such a model is simple, it has been found to be effective [Harlan and O'Brien, 1986], and it eliminates the need for additional thermal or upper air data. Brown and Zeng [1994] found that the inclusion of baroclinicity and stratification made at most a 2-hPa difference in the calculated pressures compared to when barotropic and neutral conditions were assumed. The gradient winds $(V)$ are then adjusted to geostrophic values $\left(V_{g}\right)$ with a straightforward application of the gradient wind equation,

$$
V_{g}=V\left(1+\frac{V}{f R}\right)=V(1+\mathrm{Ro}),
$$

where $R o$ is the Rossby number. If the flow is steady, it can be shown that

$$
\text { Ro }=\frac{1}{f V^{2}}\left[\left(u^{2} \frac{\partial v}{\partial x}-v^{2} \frac{\partial u}{\partial y}\right)-u v\left(\frac{\partial u}{\partial x}-\frac{\partial v}{\partial y}\right)\right],
$$

following Endlich [1961]. More generally, if the flow is not steady, a term involving time derivatives of the wind can be included, but Patoux and Brown [2002] obtained good results without this term. It should be noted that the Rossby number field requires minimal smoothing to make the gradient wind adjustment meaningful. In practice, a $225-\mathrm{km}$ low-pass binomial filter [Jähne, 1991] is applied to the satellite vorticity, and a $325-\mathrm{km}$ low-pass binomial filter is applied to the Rossby number field. Since Ro is calculated from scatterometer-derived winds, no iteration is required as in the work by Patoux and Brown [2002].

[10] Minimization of the cost function involves solving

$$
\frac{\partial F}{\partial \lambda_{i j}}=H_{i j}=0,
$$

$$
\frac{\partial F}{\partial \zeta_{i j}}=K_{\zeta} M_{i j}-\lambda_{i j}=0,
$$

$$
\frac{\partial F}{\partial p_{i j}}=\frac{1}{\rho f_{j}}\left[\nabla^{2} \lambda_{i j}-\left(\frac{\beta_{j}}{f_{j}}\right) \frac{\partial \lambda_{i j}}{\partial y}+\frac{K_{E}}{\left(2 \rho f_{j}\right)^{2}} \nabla^{2} p_{i j}\right]=0 .
$$



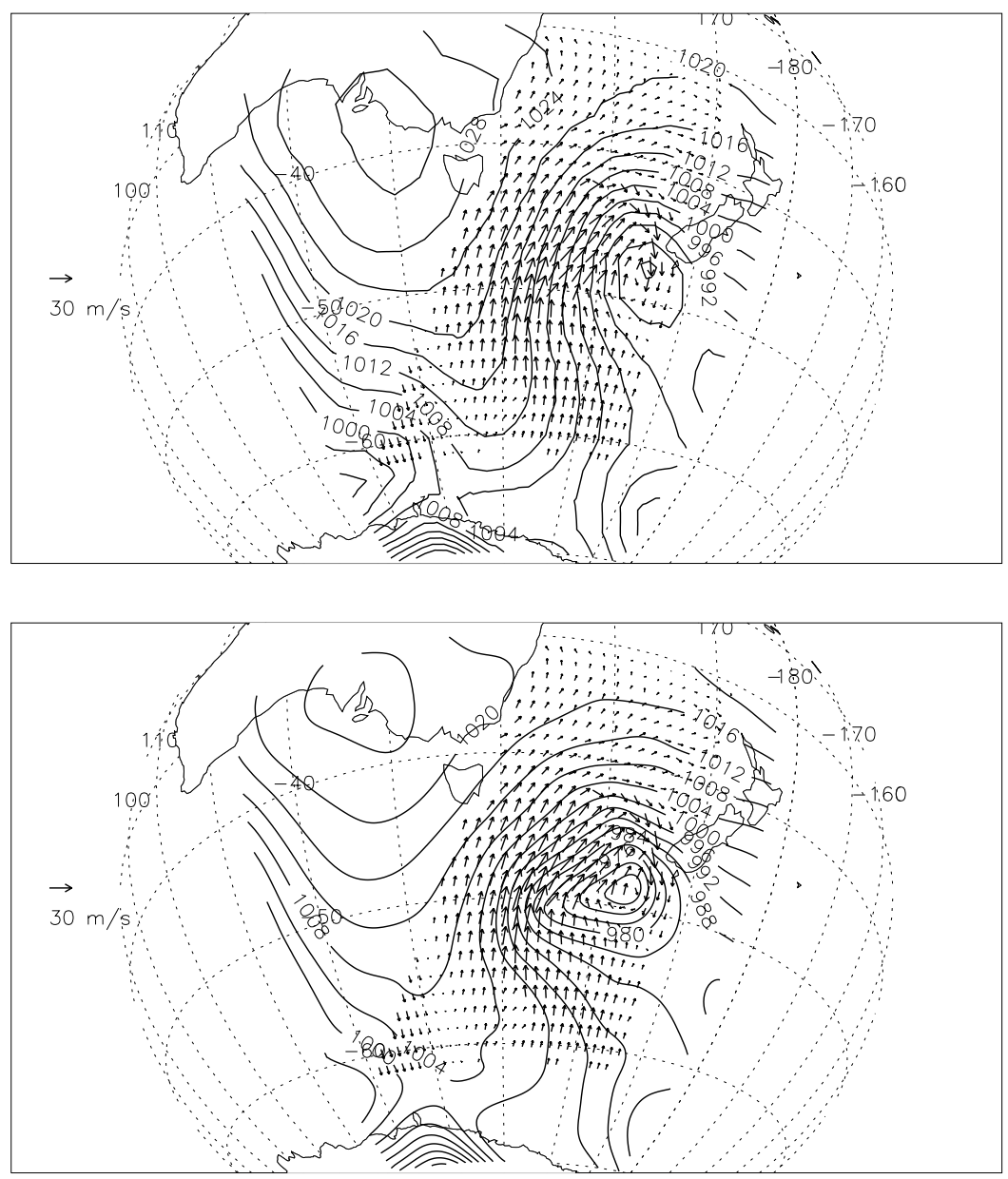

Figure 8. Same as in Figure 7 except for 06:49Z 10 June 2000. Central pressures: NCEPR 984 hPa, calculated $966 \mathrm{hPa}$.

Equation (10) has a solution of the form

$$
\lambda_{i j}=\left(\frac{K_{E}}{4 \rho f_{j}}\right)\left(p_{i j}-p_{0 i j}\right),
$$

where $p_{0 i j}$ is the homogeneous solution. The homogeneous solution satisfies

$$
\left(\frac{K_{E}}{4 \rho f_{j}}\right) \nabla^{2} p_{0 i j}=0
$$

and $\lambda=0$ on the boundaries implies $p_{0 i j}=p_{i j}$. Substituting equation (11) into equation (9) gives

$$
\zeta_{i j}=\zeta_{i j}^{*}+\left(\frac{K}{2 \rho f_{j}}\right)\left(p_{i j}-p_{0 i j}\right)
$$

where $K=K_{E} / 2 K_{\zeta}$. Putting equation (13) into equation (8) yields

$$
\nabla^{2} p_{i j}-\left(\frac{\beta_{j}}{f_{j}}\right) \frac{\partial p_{i j}}{\partial y}-\left(\frac{K}{2}\right)\left(p_{i j}-p_{0 i j}\right)=\rho f_{j} \zeta_{i j}^{*} .
$$

Equation (14) is solved using successive overrelaxation using Neumann boundary conditions. The homogeneous solution is sufficient to determine the additive constant. An optimal relaxation parameter [e.g., Press et al., 1992] of 1.8 is used along with second-order finite difference representations of the derivatives. A value of $K$ is chosen to produce a sufficiently smooth field while preserving the physical features in the SeaWinds vorticity field. Choosing higher values of $K$ produce smoother isobars and more relaxed gradients. The most appropriate value of $K$ also depends on the grid spacing and on the smoothing and adjustment of the vorticity field prior to solving equation (14). In practice, a value of $K=5.0 \times 10^{-12} \mathrm{~m}^{-2}$ is used to produce a smooth pressure field while retaining physical features in the SeaWinds geostrophic vorticity field.

\section{Validation}

[11] The region used in this study is $30-70^{\circ} \mathrm{S}$ for the 20-day period 1-20 June 2000. The calculations were performed with individual scatterometer swaths contained within a box extending $5^{\circ}$ beyond the maximum and minimum longitude points of the swath. All observations falling within this box and within 3 hours of the satellite overpass are used for validation. The observation locations 

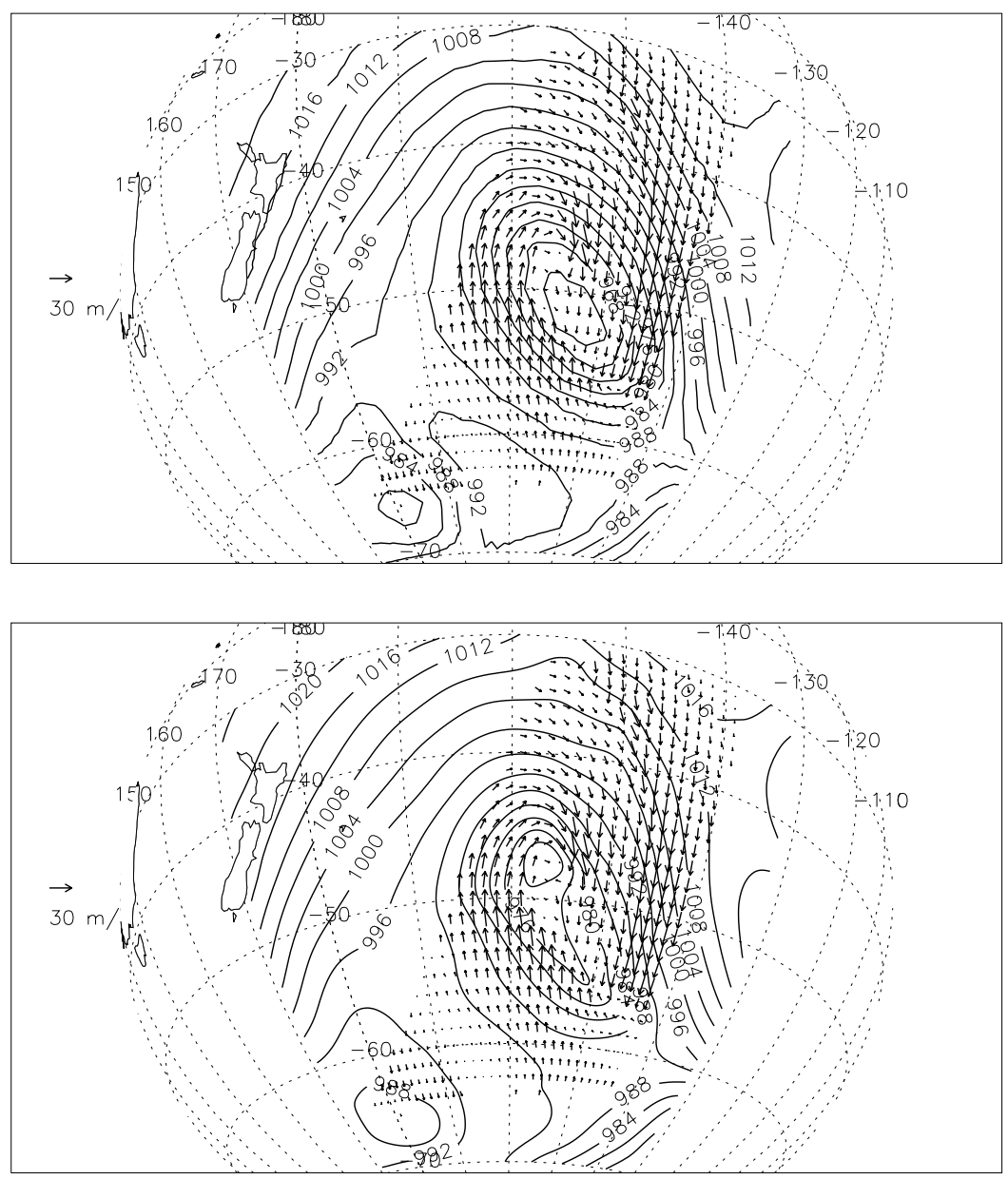

Figure 9. Same as in Figure 7 except for 03:27Z 14 June 2000. Central pressures: NCEPR $962 \mathrm{hPa}$, calculated $970 \mathrm{hPa}$.

are given at a resolution of $0.1^{\circ}$, and the surface pressures are on $0.25^{\circ}$ grids. Bilinear interpolation [e.g., Press et al., 1992] was used to interpolate from the $0.25^{\circ}$ grid to the observation location. Thus, the co-location radius was $0.15^{\circ}$ latitude $\sim 17 \mathrm{~km}$ and 3 hours. The geographic distribution of the data points used for validation is given in Figure 3.

[12] Table 1 shows that on average, the calculated and background pressures are slightly lower than the observed pressures. The statistics in Table 1 are computed at the validation points only. The calculated pressures display a little less variance than the background or observed pressures. The fourth and fifth lines in Table 1 show that the calculated pressures are slightly closer to the observations (in an RMS sense) than the background pressures. This probably understates how much closer the calculated pressures are to the truth. This is because ships tend to avoid storms (Figure 4), so cases where the scatterometer identified storms missed in the analysis (e.g., section 5) lack sufficient sampling; furthermore, it is these storms that cause the greatest synoptic scale variability in the surface pressures.

[13] Following Tolman [1998], the model uncertainty (where "model" means either the calculated or the NCEPR pressures) can be estimated using

$$
\left\langle S_{m m}^{\prime}\right\rangle=s_{m m}-\left[\frac{s_{o m}^{2}}{\left(s_{00}-\bar{s}_{00}^{\prime}\right)}\right],
$$

where $\left\langle S_{m m}^{\prime}\right\rangle$ is the expected value of the true model uncertainty, $s_{m m}$ is the estimated model variance, $s_{o m}$ is the estimated observation-model covariance, $s_{o o}^{\prime}$ is the estimated observation variance, and $s_{o o}^{\prime}$ is the estimate of the mean observation error. Figure 5 applies equation (15) for a reasonable range of observational uncertainty. Throughout most of the range, the calculated pressures are about $1.5 \mathrm{hPa}$ more accurate than the NCEPR. Note that if the observations were perfect, the calculated pressures would have an uncertainty of about $11.5 \mathrm{hPa}$. One might also ask, if the calculated pressures were perfect, what uncertainty would that imply for the observed pressures? The answer, $13.5 \mathrm{hPa}$, can either be found by deriving an equation similar to equation (15) for $\left\langle S_{o o}^{\prime}\right\rangle$ or by reading where the "calculated" curve crosses the abscissa in Figure 5.

[14] A bin-average analysis (BAA) is used to obtain a more precise idea of the observation and calculated pressure uncertainty, assuming the differences in the mean are relatively small. The BAA examines the functional relationship between the calculated minus observed pressure binned first according to the calculated pressure and then according to observed pressure. A BAA requires specification of a bin width and minimum number of data per bin. In this study a bin width of 2-hPa and minimum number of 60 datum per bin are used throughout. If the observation and calculated pressure uncertainties have been accurately deduced, then a 

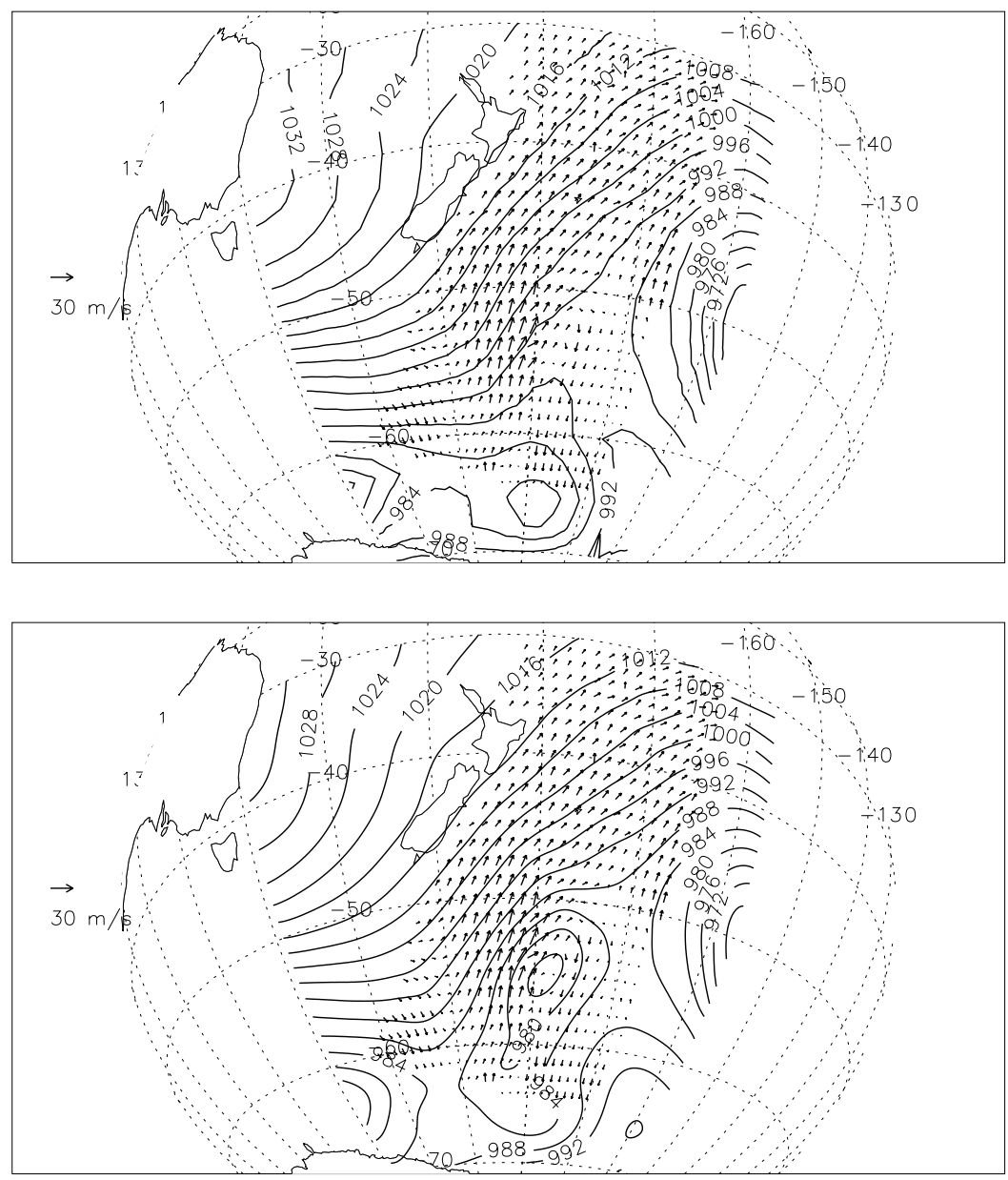

Figure 10. Same as in Figure 7 except for 05:07Z 14 June 2000. Central pressure: calculated $976 \mathrm{hPa}$.

BAA using synthetic data should replicate a BAA of the real data [Kent et al., 1998; Kent and Taylor, 1999]. Reproducibility of the BAA is a necessary, but not sufficient, condition for accurate error estimation.

[15] The synthetic data are observed surface pressures for May 2000. The same number of pressures for May 2000 are chosen as validation points in June 2000. The May pressures are then rescaled so that the range and first two moments of the May pressures are similar to the June pressures. Both the observed and the calculated pressure uncertainties need to be at least $8 \mathrm{hPa}$ for the synthetic BAA to have a broad resemblance to real BAA. The synthetic BAA most closely resembles the real BAA for an observed pressure uncertainty of $13.5 \mathrm{hPa}$ and calculated pressure uncertainty of $11.5 \mathrm{hPa}$ (Figure 6). Thus the closest BAA minimizes the calculated pressure uncertainty when considering the observations and minimizes the observation uncertainty when considering the calculated pressures. The closest BAA provides an upper bound for the observed and calculated pressure uncertainties. Thus one would expect the observed and calculated pressure uncertainties to be no larger than 13.5 and $11.5 \mathrm{hPa}$, respectively. Combining the BAA results with the uncertainty estimate from equation (15) implies observation and pressure uncertainties somewhere in the upper quadrant of Figure 5. The calculated pressure uncertainties are smaller than the observation errors for some of this quadrant, but further work would be necessary to determine if this is indeed the case.

[16] Finally, it should be emphasized that rain contamination is not responsible for the large RMS values found in Table 1. The Harlan and O'Brien [1986] technique is not sensitive to isolated patches of errors in the wind data. The regularization term suppresses the development of highwave number features in the solution pressure field. Fortunately, frontal structures and mesocyclones are of sufficient scale and are sufficiently coherent to imprint themselves on the solution pressure field.

\section{Case Study}

[17] Briefly examining the evolution of one of the storms during the study period is beneficial for understanding NCEPR deficiencies and what SeaWinds on QuikSCAT has to offer. The example also illustrates the good performance of SeaWinds on QuikSCAT in high wind conditions. The example begins on 7 June with a storm that has formed between Australia and Antarctica (Figure 7). In 3 days this storm moves eastward by about $30^{\circ}$ (Figure 8 ). The NCEPR has begun to recognize this system about to crash into New Zealand, but has a central pressure $16 \mathrm{hPa}$ higher than the scatterometer pressure field. Four days later (Figure 9), after passing New Zealand, the NCEPR represents the system 

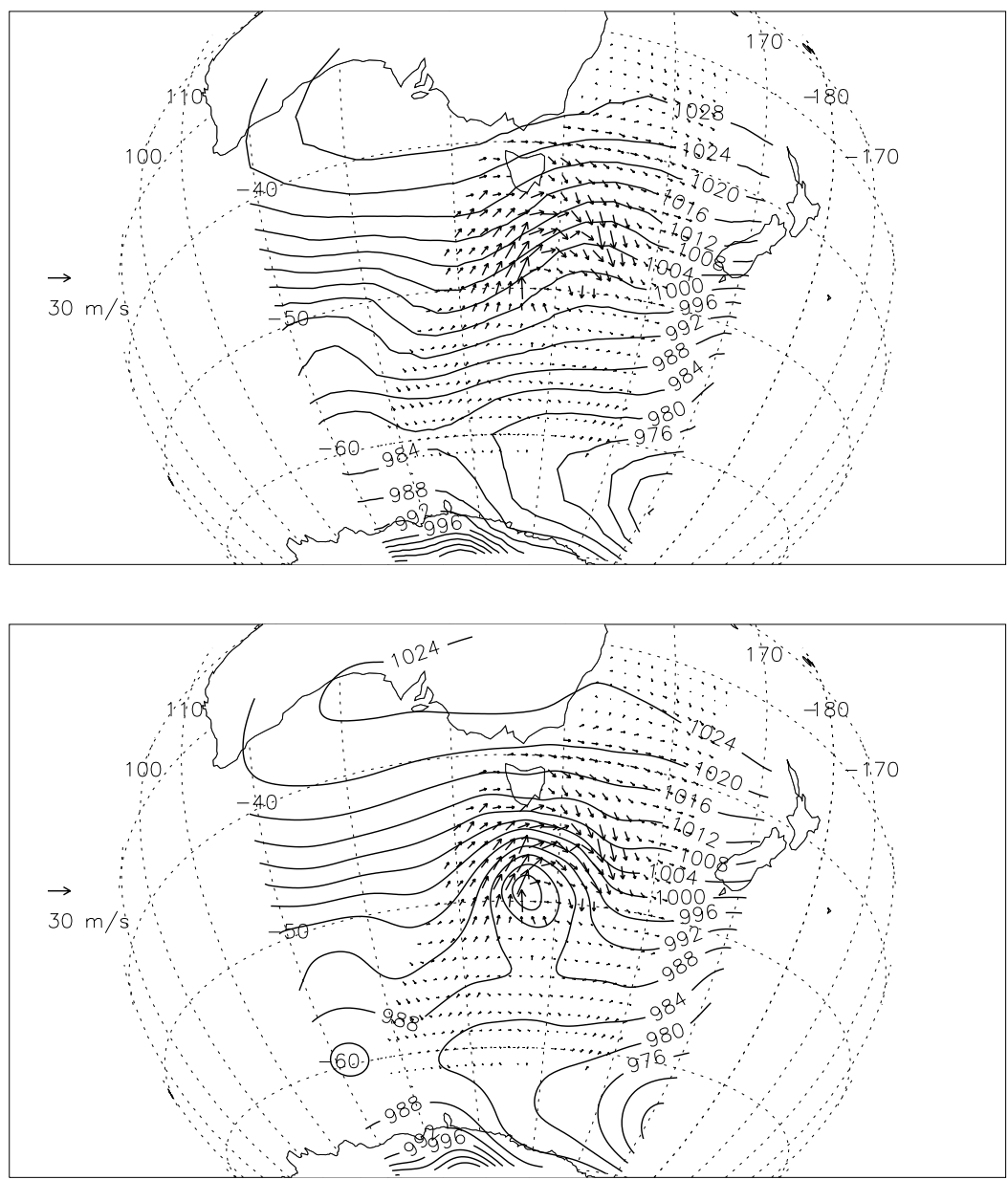

Figure 11. Same as in Figure 7 except for 07:13Z 17 June 2000. Central pressure: calculated $978 \mathrm{hPa}$. 

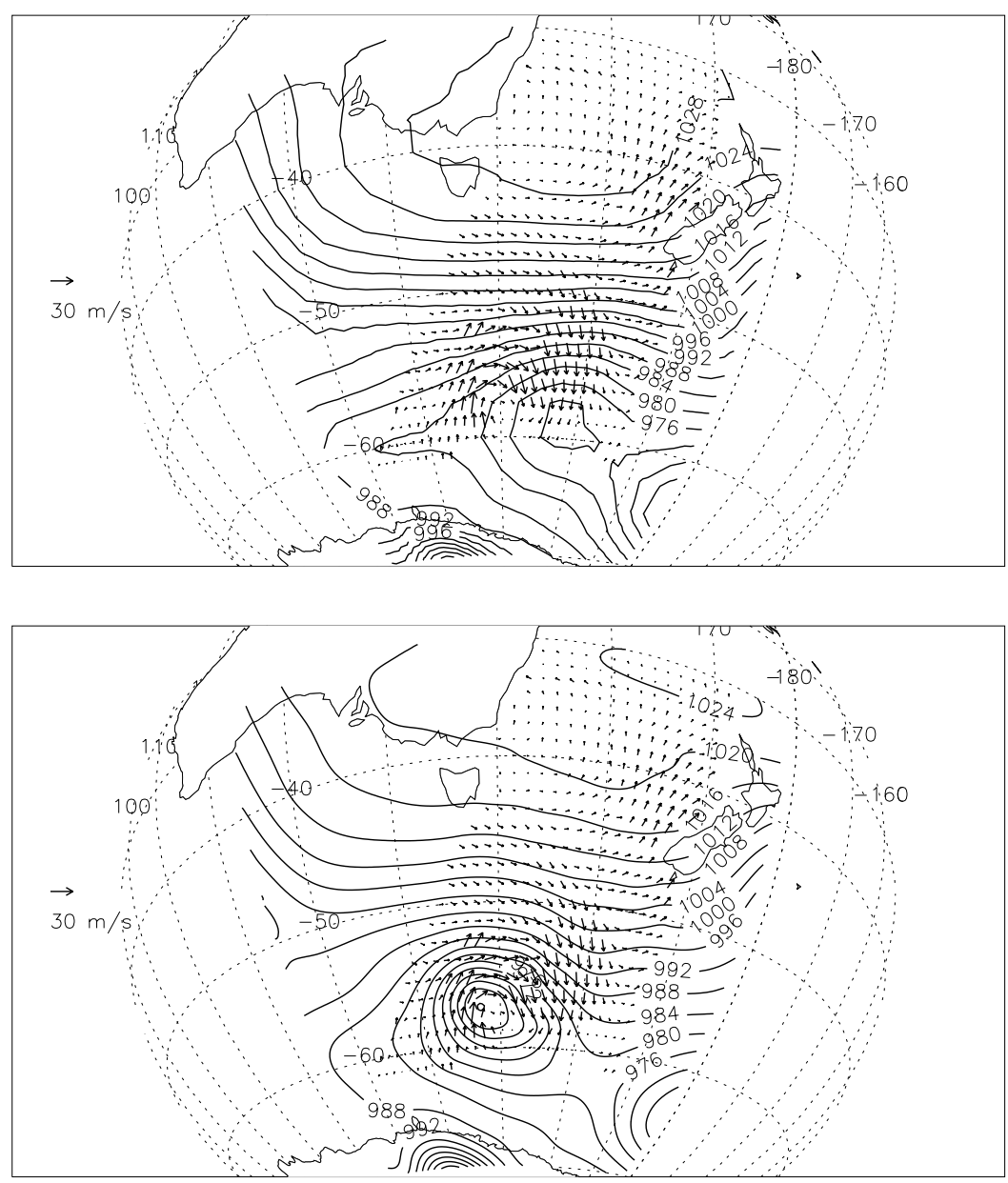

Figure 12. Same as in Figure 7 except for 06:48Z 18 June 2000. Central pressure: NCEPR 972 hPa, calculated $958 \mathrm{hPa}$.

much better; however, the NCEPR has missed a system (Figure 10) that formed just downwind of New Zealand. This cycle begins again with another system forming in the region between Australia and Antarctica (Figure 11). This system, however, dives southward (Figure 12) and continues to elude the NCEPR. Other cases similar to this one were also typical between Africa and Antarctica. The relative proximity of these systems to land highlights the importance that they be identified and tracked.

\section{Conclusions}

[18] This study has shown that the scatterometer can be effectively used to calculate high-resolution, research-quality surface pressures. This study has also shown that the scatterometer can improve upon the existing (NCEPR) analysis covering the Southern Ocean. Quantitatively, it was found that surface pressures calculated from SeaWinds on QuikSCAT winds provide a small improvement over the NCEPR. The tendency for ships to avoid storms, however, makes it likely that the true improvement is much greater, and this study presents an example showing that the SeaWinds pressures appear to be a large improvement over the NCEPR. It should be noted that the example of NCEPR missing entire storms is typical for the Southern Ocean, and a case of potential importance to the people of Australia and New Zealand.

[19] Acknowledgments. This work was supported by NASA Headquarters under the Earth System Science Fellowship grant NGT5-30370. The author has also been supported by an AMS/NASA ESE Graduate Fellowship. Support for scatterometer research came from the NASA/OSU SeaWinds project, the NASA Ocean Vector Wind Science Team (OVWST), and the National Oceanographic Partnership Program (NOPP). Data are produced by Remote Sensing Systems and sponsored, in part, by NASA's Earth Science Information Partnerships (ESIP): a federation of information sites for Earth science; and by the NOAA/NASA Pathfinder Program for early EOS products; principal investigator: Frank Wentz. The Center for Ocean-Atmospheric Prediction Studies receives its base funding from ONR's Secretary of the NAVY grant to James J. O'Brien.

\section{References}

Bourassa, M. A., M. H. Freilich, D. M. Legler, W. T. Liu, and J. J. O'Brien, Wind observations from new satellite and research vessels agree, Eos Trans. $A G U, 68,587,602,1997$.

Bourassa, M. A., D. M. Legler, J. J. O'Brien, and S. R. Smith, SeaWinds validation with research vessels, J. Geophys., 108, 3019, doi:10.1029/ 2001JC001028, 2003.

Brown, R. A., and L. Zeng, Estimating central pressures of oceanic midlatitude cyclones, J. Appl. Meteorol., 33, 1088-1095, 1994.

Endlich, R. M., Computation and uses of gradient winds, Mon. Weather Rev., 89, 187-191, 1961.

Endlich, R. M., D. E. Wolf, C. T. Carlson, and J. W. Maresca Jr., Oceanic wind and balanced pressure-height fields derived from satellite measurements, Mon. Weather Rev., 109, 2009-2016, 1981. 
Freilich, M. H., and R. S. Dunbar, The accuracy of the NSCAT1 vector winds: Comparisons with National Data Center buoys, J. Geophys. Res., $104,11,231-11,246,1999$

Harlan, J. Jr., and J. J. O'Brien, Assimilation of scatterometer winds into surface pressure fields using a variational method, J. Geophys. Res., 91, 7816-7836, 1986.

Jähne, B., Digital image processing: Concepts, algorithms, and scientific applications, 383 pp., Springer-Verlag, New York, 1991.

Kalnay, E., et al., NCEP/NCAR 40-year reanalysis project, Bull. Am. Meteorol. Soc., 77, 437-472, 1996.

Kent, E. C., and P. K. Taylor, Accounting for random errors in linear regression: A practical guide, Q. J. R. Meteorol. Soc., 125, $2789-$ 2790, 1999.

Kent, E. C., P. K. Taylor, and P. G. Challenor, A comparison of ship- and scatterometer-derived wind speed data in open ocean and coastal area, Int. J. Remote Sens., 19, 3361-3381, 1998.

Patoux, J., and R. A. Brown, A gradient wind correction for surface pressure fields retrieved from scatterometer winds, J. Appl. Meteorol., 42, $133-143,2002$.

Press, W. H., S. A. Teukolsky, W. T. Vetterling, B. P. Flannery, Numerical Recipes in FORTRAN: The Art of Scientific Computing, 2nd ed., 963 pp., Cambridge Univ. Press, New York, 1992.
Renka, R., Interpolation of data on the surface of a sphere, Rep. OLNR/ CSD-108, Oak Ridge Natl. Lab., Oak Ridge, Tenn., 1982.

Sasaki, Y., Some basic formalisms in numerical variational analysis, Mon. Weather Rev., 108, 875-883, 1970.

Tolman, H. L., Effects of observation errors in linear regression and binaverage analysis, Q. J. R. Meteorol. Soc., 124, 897-917, 1998.

Verschell, M. A., M. A. Bourassa, D. E. Weissman, and J. J. O’Brien, Ocean model validation of the NASA scatterometer winds, J. Geophys. Res., 104, 11,359-11,373, 1999.

Wentz, F. J., and D. K. Smith, A model function for the ocean-normalized radar cross section at $14 \mathrm{GHz}$ derived from NSCAT observations, J. Geophys. Res., 104, 11,499-11,514, 1999.

Zierden, D. F., M. A. Bourassa, and J. J. O'Brien, Cyclone surface pressure fields and frontogenesis from NASA scatterometer (NSCAT) winds, J. Geophys. Res., 105, 23,967-23,981, 2000.

M. Bourassa and J. O'Brien, Center for Ocean Atmospheric Prediction Studies, Florida State University, Tallahassee, FL 32306-2840, USA. (bourassa@coaps.fsu.edu; obrien@coaps.fsu.edu)

K. Hilburn, Remote Sensing Systems, 438 First Street, Santa Rosa, CA 95401, USA. (kyle@remss.com) 